Revista de Psicología de la PUCP. Vol. XIX, 2, 2001

\title{
La creación progresiva del vínculo madre-niño
}

\author{
Pierina Traverso Koroleff ${ }^{1}$ \\ Pontificia Universidad Católica del Perú
}

\begin{abstract}
Una de las líneas de investigación en salud materno-infantil se ha interesado en investigar cuáles son los indicadores del funcionamiento psicológico de las madres que llevarían a un desarrollo posterior perturbado del infante. La perspectiva del presente trabajo se distancia de esta línea de investigación. La observación natural de un infante durante el primer año de su vida, nos permite sugerir que el vínculo temprano entre una madre y su bebé se va gestando y consolidando progresivamente, más allá que el funcionamiento de la madre no sea del todo adecuado. Se sugiere además que en este vínculo afectivo temprano, la madre y el bebé se retroalimentan mutuamente. Palabras clave: observación de infantes, vínculo temprano madre-niño.
\end{abstract}

\section{The progressive creation of the early mother-child bonding}

One of the research areas in mother-child health has focused on examining which are the signs in mothers' psychological functioning that would lead to a further disturbed development in an infant. The perspective of this paper has deviated from this research area. Natural observation of an infant during his/her first year of life suggests that early mother-child affective bonding grows and strengthens progressively, even mother's behavior is not totally adequate. This article also suggests that mother and child feed back each other in this early bonding.

Keywords: infant observation, early mother-child bonding.

1 Profesora Auxiliar en la sección de Psicología de la PUCP, se desempeña actualmente como psicoterapeuta. Es Magíster en Psicología por la Universidad de Nueva York y licenciada en psicología clínica por la PUCP. Correo electrónico: ptraver@pucp.edu.pe. 

Existen varios estudios sobre salud materno-infantil interesados en investigar cuáles son los indicadores de funcionamiento psicológico de las madres que llevarían a un vínculo madre-niño inadecuado $y$, por tanto, a un desarrollo posterior perturbado del infante.

Nuestro trabajo se inserta en otra perspectiva, menos limitante y más integradora. A partir de nuestras observaciones sugerimos que el vínculo temprano entre una madre y su bebé se va gestando y consolidando progresivamente, más allá de que el funcionamiento de la madre no sea del todo adecuado. En este vínculo afectivo temprano, madre y bebé se retroalimentan mutuamente.

Ser una madre suficientemente buena, como diría Donald Winnicott (1981), es una tarea difícil más no imposible. Lo cierto es que para algunas mujeres - por su propia circunstancia e historia personal-, el primer año de vida de sus bebés les genera una serie de angustias y fantasías (Raphael-Leff, 1995); y las pone en contacto - como manifiesta Raphael-Leff (1994) - con sus cosas salvajes, es decir, con los aspectos más primitivos de la personalidad que no han sido del todo elaborados.

$\mathrm{Al}$ desarmar las defensas adultas, un bebé obliga a su madre o padre a reexperimentar lo que es sentirse impotente, necesitado, frustrado, furioso, atormentado, abandonado, traicionado. (Raphael-Leff, 1994:35)

Lo primero que quisiéramos plantear en estas páginas es la idea de que pese a lo difícil que pueda ser la maternidad para una mujer - sobre todo durante el primer año de vida del bebé-, por lo general (a menos que haya un trastorno psiquiátrico o que la madre se halle en un grupo de alto riesgo, por ejemplo, madres adolescentes), la madre se irá encontrando progresivamente con su hijo por caminos 
que no son siempre los más esperados. En este sentido, Parker (1997) en un artículo sobre ambivalencia materna, sugiere que no hay una línea normal, fija o correcta de desarrollo maternal.

En segundo lugar quisiéramos mostrar siguiendo a los teóricos del desarrollo, cómo el bebé juega un rol activo en este encuentro afectivo con la madre (Stern, 1991, 1997). Finalmente, es la propia novedad de su relación con este bebé que ayuda a la madre a descubrir facetas de sí misma no percibidas hasta ese momento (RaphaelLeff, 1994).

En tercer lugar pretendemos sugerir en este trabajo, que la red de soporte social que rodea a la madre y al bebé se vuelven elementos facilitadores que repercuten e inciden positivamente en el vínculo madre-niño. Muchas veces es la misma madre que por sus propias carencias, limitaciones o déficits escoge (consciente o inconscientemente) rodearse de personas que le faciliten su tarea materna.

Esta propuesta se enmarcó dentro de un seminario de observación de infantes. En este se siguió el desarrollo de un bebé desde que nació hasta que cumplió un año. Las observaciones se llevaron a cabo semanalmente durante 50 minutos en la casa del bebé. Uno de los objetivos de este seminario fue poder observar el desarrollo del vínculo afectivo entre la madre y su bebé. Luego de la observación se transcribió el material detalladamente. La observación estuvo mediatizada por los sentimientos que le generaba al observador participar en la intimidad del encuentro entre una madre y su bebé. Cada semana los participantes del seminario se reunían con un psicoterapeuta de niños para estudiar el material.

Las observaciones se iniciaron cuando Billy tenía tres semanas de nacido. Billy era el tercer hijo varón de Carla (38 años). Sus otros hijos varones tenían 14 (Mark) y 9 (Paul) años, respectivamente. Carla era latinoamericana. En un viaje que hizo al Perú conoció a su actual esposo y desde su matrimonio residía en Lima. 
Aunque ambos padres trabajaban y Carla tenía un pequeño negocio propio, la familia no gozaba de una situación económica del todo favorable. Sin embargo, vivía en un departamento (120 metros cuadrados aproximadamente) de tres dormitorios en una zona residencial de Lima. Cabe agregar que el embarazo no había sido deseado.

Para Stern (1997) el bebé desde el comienzo de su vida tiene capacidades para relacionarse que van cambiando y sofisticándose a lo largo del primer año de vida. Estas capacidades a su vez permiten observar el nuevo campo interaccional entre el bebé y los otros. Stern manifiesta que cada avance en una competencia interaccional provee al observador diferentes ventanas clínicas para mirar el progreso de los principales hitos en el curso de la vida.

En el presente trabajo vamos a utilizar como referente el concepto de Stern de ventanas clínicas, no solo para analizar las interacciones, sino a su vez para guiarnos a través de las diferentes vicisitudes que acontecieron en el primer año de vida de esta madre y su bebé.

\section{Primera ventana clínica: entre los 0 y dos meses y medio}

Stern (1997) refiere que en esta etapa la alimentación y/o el sueño y episodios de llorar y calmar constituyen los hitos más relevantes. Las tareas interaccionales básicas constituyen la alimentación del bebé, el sueño-vigilia, los ciclos de actividad y la mayoría de los intercambios sociales ocurren alrededor de estas actividades.

En el caso de Billy y su mamá, estos dos primeros meses se caracterizaron por el episodio de mastitis y el posterior destete antes del segundo mes. Se percibía que a Carla el vínculo más cercano con el bebé, a través de la lactancia, le producía mucha angustia. Dar de lactar dolía, había algo en el contacto que resultaba doloroso. No había un lugar ni un tiempo para la intimidad del encuentro en las primeras 
semanas. Carla manifestaba: "Yo soy una persona muy activa y la lactancia interrumpe mi organización".

Raphael-Leff (1995) dice que existe un tipo de madre que es la reguladora. Este tipo de madre se ve como separada y autónoma de su bebé. La madre reguladora no se entrega a lo doméstico y quiere volver al mundo real lo antes posible. A diferencia de la madre facilitadora que quiere gratificar todos los deseos del bebé, la tarea de la reguladora es socializar al bebé que asume como un ser pre-social. La madre reguladora no se presenta como única cuidadora, sino se presenta como una figura más de las figuras que van a cuidar al bebé. Mientras que la madre facilitadora se adapta al bebé, la reguladora quiere que el bebé se adapte al estilo de la casa.

Carla era el tipo de madre reguladora. A las pocas semanas empezó a trabajar y delegó casi enteramente el cuidado físico y emocional del bebé a Rosa, la niñera. Rosa era una mujer tranquila, callada, de unos 40 años, pero que le daba a Billy toda la predictibilidad y constancia que no recibía de su madre.

Según Magagna (1997), la niñera ideal sería aquella que contiene las angustias de la madre y le facilita a esa madre, ser madre sin entrar en rivalidades por el bebé. La madre tiene una imagen de lo que es una buena cuidadora y eso determina su elección consciente de una determinada niñera. Rosa y Carlà se complementaban. No competían por el niño y Rosa aceptaba de buen grado las diferencias y sugerencias de Carla.

Antes que ver a Carla como una madre poco empática, creemos que para ella fue necesario emocionalmente delegar el cuidado del bebé a la niñera (alimentación, sueño, limpieza, baño, etc.) ya que los contactos más cercanos eran perturbadores, dada su experiencia previa de maternidad. 
[...] cuando tienes tu primer hijo te entregas totalmente a él , yo estaba sola en Lima, me volqué por completo con Mark, pero justamente depender tanto trae malas consecuencias. Desde niño, Mark tuvo problemas de tonicidad muscular, era muy retraído, con muchos problemas de socialización. Justamente al hijo que más me apegué, más le di, salió con tantos problemas.

Carla sentía que había algo en ella que dañaba y no daba niños sanos. La dependencia producía malos resultados, la otra alternativa era la opuesta: la independencia precoz y delegar a otros.

Nos preguntamos qué rol jugó el padre en el desarrollo de Billy. Solo tuvimos oportunidad de ver al padre de Billy en dos ocasiones: en el hospital cuando recién Carla acababa de dar a luz y en el primer cumpleaños de Billy. Por lo que refieren Carla y la niñera, el padre quería mucho a Billy, se alegraba mucho con su presencia y parece que había sido un revitalizador para él.

Mark, el hermano mayor, también jugaba un papel importante en el crecimiento de Billy, a pesar de ser un joven inmaduro emocionalmente para su edad. Mark le daba a su hermano todo el cariño que su madre no le podía ofrecer a Billy. Mark proyectaba su parte más carente y necesitada en este bebé.

\section{La segunda ventana clínica: entre los 2 meses y medio y los 5 meses y medio}

Stern (1997) refiere que en esta etapa lo importante es la interacción social cara a cara (sin juguetes u otros objetos).

En las ocasiones que Carla cuidaba a Billy, ella podía ponerse en el lugar del bebé, mostrarse orgullosa de sus logros; sin embargo, la interacción en estos meses era más bien superficial y un tanto forzada. Muchas veces parecía que Carla estaba en otra parte muy lejos. 
Carla no sabía de dónde aparecían los nuevos juguetes o las nuevas prendas que tenía Billy. Se desconcertaba ante las nuevas habilidades de su hijo o ante los pequeños malestares que este tenía en lo cotidiano. Rosa era siempre su referente que contenía su desconcierto.

Mientras tanto, Billy seguía creciendo a su propio ritmo. Él era un niño de temperamento fácil (Thomas y Chess, 1977), sonriente y observador. Parecía que se adaptaba demasiado fácilmente a su medio. En los cinco primeros meses lloraba y se quejaba poco. En estos meses, Billy comenzó a sonreírle frecuentemente a su mamá. Cuando Carla se alejaba emocionalmente de él, este la reclamaba y la traía nuevamente a la interacción. Esto ocasionaba que Carla pudiese estar un poco más pendiente de él y pudiese decodificar mejor sus mensajes pre-verbales.

Carla siempre preguntaba a la observadora cómo veía al bebé. Necesitaba apoyarse en un otro que le reconfirmara que ella estaba siendo una buena madre y que Billy estaba logrando los hitos maduracionales para su edad. Así, Carla le comenta a su hijo mayor: Billy es un bebé sano que está creciendo bien, porque está bien cuidado. Luego le pregunta a la observadora: ¿No es cierto?

Estas actitudes de inseguridad frente a su rol materno se combinaban con actitudes mucho más asertivas, en las cuales ella sabía por su experiencia qué era lo que necesitaba su bebé. De algún modo estas actitudes más asertivas balanceaban su perplejidad ante el encuentro con un ser tan frágil (pero no pasivo) como es un bebé.

En muchas ocasiones la observadora llegaba al cuarto del bebé y encontraba música de un casete de niños que era puesta por la niñera o por la madre. La observadora tenía la sensación que estaba música trataba de levantar el ambiente o de llenar un vacío.

Carla pone música y dice: "con la música Billy se acompaña porque sino se siente solo". Tan pronto como dice esto, inmediatamente 
cambia de tema y me dice que Billy es un niño estimulado que tiene alguien que lo cuide todo el rato y que tiene todo lo que necesita, mientras que hay otros niños que no pueden tener el lujo de tener una niñera.

En alguna parte de su mundo interno, Carla sentía que ella no podía sostener y acompañar lo suficientemente bien a Billy, que ella sola no podía proporcionarle su propia música. La cita anterior también nos revela el impacto que sus propias palabras tienen sobre sí misma, rápidamente necesita tranquilizarse y autoconvencerse que ella es la adecuada madre adulta y que todo está bien para Billy.

\section{La tercera ventana clínica: entre los 5 meses y medio y los 9 meses}

Según Stern ( 1997), esta etapa nos permite ver cómo el progenitor y el niño juegan con objetos inanimados.

Por estos meses ocurrieron varios eventos significativos en la vida de Billy: malestares físicos recurrentes (fiebres, diarreas, otitis), dos viajes de su mamá al exterior debido a su negocio y trastornos de la alimentación: básicamente una inapetencia que llevó a una baja de peso de dos kilos.

Billy sufrió de otitis mientras su mamá estuvo de viaje. Este período coincidió con el hecho de que Billy se volvió más llorón y chinchoso, a decir de su madre. La observadora sentía que finalmente este niño había empezado a protestar cuando no estaba atendido o cuidado suficientemente bien.

Billy comenzó a desplegar su fuerza muscular entre los seis y siete meses. Se sentaba, gateaba, se paraba. Cogía los objetos con más firmeza, los investigaba, se concentraba más en ellos. El juego de a dos era básicamente con Rosa, la niñera. Carla observaba los logros de su hijo en este terreno, pero casi no participaba. 
Carla toleraba mejor los aspectos más dóciles y tranquilos de Billy, pero le era difícil contener las protestas o el llanto. A continuación una viñeta que describe lo dicho anteriormente, un día que la niñera había salido.

En algún momento, Billy está parado y se cae, comienza a llorar. Mark, su hermano, lo carga, lo besa, lo apachurra, pero Billy no para de llorar. Ante el llanto viene Carla, carga a Billy pero este sigue llorando, no sabe qué hacer, lo pone en su silleta, Billy no quiere estar allí. Ella se ríe, medio desencajada. No aguanta mucho con el bebé, no tiene paciencia para calmarlo, para calmarse ella también. Me dice: "¿que pensarás de Billy?". Le digo que está empezando a reclamar cuando está disgustado, incómodo por algo. Carla está desesperada pues el bebé sigue llorando. Lo mete a su cama y es peor. Carla me dice algo que no llego a entender bien: "Nosotros somos gente buena, pero hay veces...". En la cuna Billy da patadas, Carla lo saca y llama a la empleada. La empleada lo pone en sus brazos, al principio el bebé sigue llorando, pero al poco rato se calma. Carla agitada me dice que tiene una cita en el dentista y sale apurada".

Raphael-Leff (1995) refiere que el llanto de un bebé puede ser contagioso para la madre ya que puede abrir las compuertas de sus propias emociones; la madre puede "ser inundada por lágrimas provenientes de un orificio destapado en lo más profundo de sí misma y que nunca dejan de fluir" (p. 38). La madre siente la necesidad de levantar una barrera sólida entre ellos, haciendo más rígidos sus límites para mantener fuera al bebé.

Carla se sintió impotente, desesperada por el llanto de su bebé no pudo permanecer sola con él, estaba temerosa de perder el control, y ponerse a llorar y rabiar como el niño. Carla salió en busca de la empleada casi como una forma de proteger a su hijo de su propio salvajismo, en términos de Raphael-Leff, y protegerse a sí misma. 
La inapetencia de Billy hacia los ocho meses refleja también a nuestro entender una forma de protesta ante la ausencia de su madre. Por esos días se le veía a Billy algo triste y delgado. Su imagen contrastaba con la que habitualmente tenía: un niño sonriente. Carla se percató de este adelgazamiento, llevó a Billy a hacerse una serie de exámenes médicos, pero no se encontró ningún problema físico. Carla sabía que algo pasaba con su bebé de allí los exámenes médicos, pero su angustia - de no ser una adecuada madre - no le permitía responder emocionalmente al pedido que le hacía Billy con su inapetencia. En cambio, respondía defensivamente con un: a todos los niños les pasa[...].

\section{La cuarta ventana clínica: entre los 8 meses y el año}

Stern (1997) refiere que en esta etapa existen dos acontecimientos que permiten observar claramente las interacciones entre padres e hijos. El primer acontecimiento es el apego. Hacia finales del primer año, el niño muestra conductas características de vínculo y separación del principal progenitor. Este proceso se acelera por la capacidad del niño de distanciarse y acercarse a través de sus nuevas conductas motoras adquiridas: el gateo y luego caminar. Stern refiere que es interesante observar cómo a través del apego padres e hijos negocian el espacio entre la distancia y la cercanía.

El segundo acontecimiento se refiere a la aparición de la intersubjetividad:

[...] el niño se da cuenta de que la madre puede tener cosas en la cabeza, es decir, contenidos mentales como cierta atención a algo, una intención, un efecto, y se da cuenta de que él también los tiene, pudiendo ser los contenidos de su mente y de la mente de la madre iguales o diferentes. Si no son iguales, pueden alinearse. (p. 74) 
Cuando Billy comenzó su exploración por el mundo, fue Rosa la que negoció sobre todo la distancia óptima. Cuando Carla se hacía cargo del bebé muchas veces andaba abstraída en sus propios pensamientos y el bebé desaparecía ante ella y probablemente también su madre desaparecía para Billy en ese momento necesario para proseguir la búsqueda.

Sin embargo, a medida que Billy fue creciendo, Carla se fue acercando más a él. Se le veía más contenta y relajada con él. Se sentaba más a jugar con Billy. Probablemente, el hecho de que Billy fuese menos frágil le permitía a Carla una mayor cercanía. No obstante, creemos también que lo que posibilitó esta cercanía fue que Billy fue respondiendo al diálogo de dos, conectándose a su madre con gestos e intenciones y desarrollando una intersubjetividad única entre ambos.

En un momento mientras Carla está jugando con Billy y este se ríe con ella, me dice: este niño es tan bueno que no parece mi hijo, claro que es mi hijo, es que es tan dulce [...].

Carla comenzó a proyectar sus aspectos más positivos en Billy. Brazelton y Cramer (1993) refieren que en la práctica clínica con bebés se puede observar los aspectos adaptadores como los destructivos de la proyección. Cierto grado de proyección cimienta la relación: los padres le adjudican al bebé las características que más valoran y lo premian y aman por cualquier conducta suya que confirme esta imagen positiva. Carla le adjudicaba al bebé una serie de cualidades que probablemente partían objetivamente del temperamento de Billy, pero también que Carla proyectaba inconscientemente en el bebé.

Carla abraza a Billy y dice: “¿por qué será que lo quiero tanto? Es tan hacendoso este chiquito".

"Es un niño que tiene ángel, carisma. Mis amigas me dicen que es especial. Billy se parece a mí, no en lo físico, sino en el carácter. Es muy activo, siempre está haciendo algo, mientras que Mark era más pasivo y Paul tiene otro carácter". 
Billy fue un promotor activo de este encuentro progresivo entre su madre y él. Sin embargo, cabe preguntar ¿en qué medida Billy se adaptó a lo que Carla quería de él? Es decir, en un niño relativamente tranquilo y sonriente? ¿En qué medida esta adaptación "precoz" se hizo a costa de sus propias necesidades emocionales? ¿Fue Billy un "reanimador" (Stern, 1997) de los aspectos más depresivos de Carla?

En realidad, no podemos contestar a estas preguntas con certeza. Lo cierto es que hacia finales del primer año, el vínculo entre Carla y Billy fue de una mejor calidad, a pesar de que Billy siguió enfermándose con relativa frecuencia y era inapetente.

Finalmente, en este encuentro progresivo entre Carla y Billy quisiéramos enfatizar el rol que juegan los soportes sociales para promover el vínculo madre-niño y el desarrollo del bebé (Álvarez, 1992). En nuestro caso, la presencia de los hermanos, la niñera y el padre jugaron papeles importantes en facilitar a la madre el cuidado del bebé y en sostenerlo afectivamente para que pudiese, quizás, ser un niño con más recursos para acercarse a su madre.

\section{Referencias}

Álvarez, A. (1992). Live company. Londres: Routledge.

Brazelton, T. B. y Cramer, B. G. (1993). La relación más temprana: padres, bebes y el drama del apego inicial. Barcelona: Paidós.

Magagna, J. (1997). Shared unconscious and conscious perceptions in the nanny-parent interaction, which affect the emotional development of the infant. En S. Reid (Ed.). Developments in infant observation: the Tavistock Model (pp. 33-55). Londres: Routledge.

Parker, R. (1997). The production and purposes of maternal ambivalence. En W. Hollway y B. Featherstone (Eds.). Mothering and ambivalence (pp.17-36). Londres: Routledge. 
Raphael-Leff, J. (1994). El lugar de las cosas salvajes. En M. Lemlij (Ed.). Mujeres por mujeres (pp. 31-45). Lima: Biblioteca Peruana de Psicoanálisis.

Raphael-Leff, J. (1995). Pregnancy: the inside story. Nueva Jersey: Jason Aronson.

Stern, D. (1997). La constelación maternal: la psicoterapia en las relaciones entre padres e hijos. Barcelona: Paidós.

Stern, D. (1991). El mundo interpersonal del infante: una perspectiva desde el psicoanálisis y la psicología evolutiva. Barcelona: Paidós.

Thomas A. y Chess, S. (1977). Temperament and development. Nueva York: Brunner/Mazel.

Winnicott, D. (1981). Escritos de Pediatría y Psicoanálisis. Barcelona: Editorial Laia. 